\title{
Novel oral anticoagulants for the prevention of thromboembolism in patients with atrial fibrillation
}

\author{
${ }^{1} \mathrm{NN}$ Lang, ${ }^{2} \mathrm{DT}$ Connelly \\ ${ }^{1}$ Clinical Research Fellow; ${ }^{2}$ Consultant Cardiologist, Department of Cardiology, Golden Jubilee National Hospital, Clydebank, Scotland
}

This review is based in part on Dr Connelly's lecture at the RCPE Cardiology Symposium held on I5 November 2012 at the Royal College of Physicians of Edinburgh

\begin{abstract}
The most significant complication of atrial fibrillation (AF) is thromboembolic stroke. Furthermore, the consequences of AF-related stroke tend to be more severe than those of other aetiologies. The need for safe, effective and convenient anticoagulation is clear. Warfarin is the current mainstay of treatment but its prescription and use remains sub-optimal, despite clear evidence and guidance to support its use. Many patients taking warfarin spend a significant amount of time subtherapeutically anticoagulated and the requirement for regular monitoring of warfarin's anticoagulant activity is both inconvenient and costly.
\end{abstract}

Novel oral anticoagulants promise more predictable and convenient anticoagulation. They have potential superiority over warfarin for preventing thromboembolic stroke and appear to be associated with fewer haemorrhagic effects. Understanding the important background to the novel agents presents an opportunity to tailor anticoagulant treatment to the individual. This should allow a greater proportion of the eligible population access to effective anticoagulation. Furthermore, it should reduce their exposure to the risk of both thromboembolic and haemorrhagic stroke and their potentially devastating consequences.

KEYWORDS Anticoagulants, atrial fibrillation, thromboembolism

DECLARATION OF INTERESTS No conflicts of interest declared.

\author{
Correspondence to NN Lang \\ Scottish Advanced \\ Heart Failure Service \\ Golden Jubilee National \\ Hospital, Agamemnon Street \\ Glasgow G8I 4DY, UK
}

tel. $+44(0) 1419511000$

e-mail ninian.lang@me.com
Atrial fibrillation (AF) is common and its prevalence is rising in parallel with increased life expectancy and an ageing population. Indeed, it is the most common sustained arrhythmia and one in four people over the age of 40 years will develop AF within their lifetime.' International data reflect a $0.9 \%$ population prevalence that rises to between $3 \%$ and $5 \%$ in those aged over 65 years and to more than $10 \%$ in octogenarians. ${ }^{1,2}$ Consistent data has been reported from the large Renfrew/Paisley cohort of over 15,000 Scottish people. ${ }^{3}$

\section{ATRIAL FIBRILLATION AND STROKE}

Interventional techniques and, to an extent, pharmacotherapies have advanced to reduce symptoms directly associated with AF burden. However, the prevention of thromboembolic complications (primarily stroke) remains the over-riding priority. In the Framingham study, individuals with AF were at between four- and five-fold greater risk of stroke than those without. ${ }^{4}$ This risk is further amplified in the context of additional risk factors including, but not limited to, diabetes mellitus, systemic hypertension or heart failure. In those aged 80-89 years, AF is responsible for just under $25 \%$ of all strokes. ${ }^{4}$

Patients who suffer a stroke in the context of AF are more likely to die or suffer permanent disability. In an illuminating study performed prior to the advent of thrombolysis for the treatment of stroke, Lin et al. observed a 30 -day mortality of $14 \%$ in patients with strokes occurring in the absence of AF, while $25 \%$ of those with AF-associated stroke were dead at 30 days. Furthermore, survivors of AF-related stroke had more recurrent cerebral ischaemic events and greater disability than those with non AF-associated stroke. ${ }^{5}$

\section{VITAMIN K ANTAGONISTS}

Since the 1950s, vitamin K antagonists (coumarin and its derivatives, primarily warfarin) have been the mainstay for use in oral anticoagulant therapy. They are highly 
effective in the reduction of ischaemic stroke in patients with $\mathrm{AF}$, reducing the risk of stroke by $64 \%$ in comparison to placebo and by $37 \%$ when compared with antiplatelet therapy. ${ }^{6}$ Further, the anticoagulant effect of warfarin is readily reversed by the administration of vitamin $\mathrm{K}$ and its anticoagulant effect is easily measured using the International Normalised Ratio (INR). Despite these favourable properties, warfarin has significant constraints that have caused problems with its use and limited its uptake even in groups at high risk for thromboembolic complications of AF.

Scoring systems such as the $\mathrm{CHADS}_{2}$ (congestive heart failure, hypertension, age, diabetes mellitus, stroke or transient ischaemic attack [TIA] or thromboembolism) and $\mathrm{CHA}_{2} \mathrm{DS}_{2}$-VASc (age 65-74, female, vascular disease) risk prediction models (Tables $I A$ and $B$ and $2 A$ and $B$ ) for thromboembolic risk in AF have been developed and validated. ${ }^{7}$ They have been incorporated into major national $^{8,9}$ and international ${ }^{10,11}$ guidelines with the recommendation that patients at moderate or high risk of stroke should be anticoagulated (Figure I).

\section{TABLE IA CHADS, score criteria}

\begin{tabular}{|l|c|}
\hline CHADS $_{2}$ risk factor & Score \\
\hline Congestive heart failure & $\mathrm{I}$ \\
\hline Hypertension & $\mathrm{I}$ \\
\hline Age $>75$ years & $\mathrm{I}$ \\
\hline Diabetes mellitus & $\mathrm{I}$ \\
\hline Stroke or transient ischaemic attack & 2 \\
\hline
\end{tabular}

TABLE I B $\mathrm{CHA}_{2} \mathrm{D}_{2}$-VASc score criteria

\begin{tabular}{|c|c|}
\hline CHADS $_{2}$ VASc risk factor & Score \\
\hline $\begin{array}{l}\text { Congestive heart failure or left ventricular } \\
\text { ejection fraction } \leq 40 \%\end{array}$ & 1 \\
\hline Hypertension & 1 \\
\hline Age $>75$ years & 2 \\
\hline Diabetes mellitus & I \\
\hline $\begin{array}{l}\text { Stroke/transient ischaemic attack/ } \\
\text { thromboembolism }\end{array}$ & 2 \\
\hline $\begin{array}{l}\text { Vascular disease (prior myocardial } \\
\text { infarction, peripheral arterial disease, aortic } \\
\text { plaque. }\end{array}$ & I \\
\hline Age $65-74$ years & 1 \\
\hline Sex category (female) & 1 \\
\hline
\end{tabular}

\section{Warfarin is under-prescribed}

Prescription and compliance with anticoagulation therapy remain disappointingly low. Notably, the Euro Heart Survey of AF patients revealed that only $67 \%$ of patients eligible for anticoagulation received this therapy
TABLE 2A CHADS, score and stroke rate.Adapted from the European Society of Cardiology guidelines for the management of atrial fibrillation (2010). ${ }^{10}$

\begin{tabular}{|c|c|c|}
\hline CHADS $_{2}$ score & $\begin{array}{c}\text { Patients } \\
(\mathbf{n = 1 , 7 3 3 )}\end{array}$ & $\begin{array}{c}\text { Adjusted stroke } \\
\text { rate \%/year }\end{array}$ \\
\hline 0 & 120 & 1.9 \\
\hline 1 & 463 & 2.8 \\
\hline 2 & 523 & 4.0 \\
\hline 3 & 337 & 5.9 \\
\hline 4 & 220 & 8.5 \\
\hline 5 & 65 & 12.5 \\
\hline 6 & 5 & 18.2 \\
\hline
\end{tabular}

TABLE 2B CHA $\mathrm{D}_{2}$-VASc score and stroke rate

\begin{tabular}{|c|c|c|}
\hline CHADS $_{2}$ score & $\begin{array}{l}\text { Patients } \\
(n=7,329)\end{array}$ & $\begin{array}{l}\text { Adjusted stroke } \\
\text { rate \%/year }\end{array}$ \\
\hline 0 & $\mathrm{I}$ & 0 \\
\hline 1 & 422 & 1.3 \\
\hline 2 & 1,230 & 2.2 \\
\hline 3 & 1,730 & 3.2 \\
\hline 4 & 1,718 & 4.0 \\
\hline 5 & 1,159 & 6.7 \\
\hline 6 & 679 & 9.8 \\
\hline 7 & 294 & 9.6 \\
\hline 8 & 82 & 6.7 \\
\hline 9 & 14 & 15.2 \\
\hline
\end{tabular}

and further concern remains that 'real world' prescribing is likely to be even lower. ${ }^{12,13}$ Reasons cited for the under-prescription of anticoagulants consistently include fear of precipitating bleeding. Although this can be a valid concern, it may also be overstated. Furthermore, the elderly are under-represented in anticoagulant treatment and are the very group who stand to benefit the most. ${ }^{14}$

TABLE 3 HAS-BLED scoring tool for the assessment of bleeding risk. From European Society of Cardiology guidelines for the management of atrial fibrillation (2010). ${ }^{10}$

\begin{tabular}{|l|l|c|}
\hline Letter & Clinical characteristic & $\begin{array}{l}\text { Points } \\
\text { awarded }\end{array}$ \\
\hline H & Hypertension & I \\
\hline A & $\begin{array}{l}\text { Abnormal liver function and } \\
\text { abnormal renal function } \\
\text { (I point each) }\end{array}$ & I or 2 \\
\hline S & Stroke & I \\
\hline B & Bleeding & I \\
\hline L & Labile international normalised ratios & I \\
\hline E & Elderly (e.g. age $>65$ years) & I \\
\hline D & $\begin{array}{l}\text { Drug or alcohol misuse } \\
\text { (I point each) }\end{array}$ & I or 2 \\
\hline
\end{tabular}




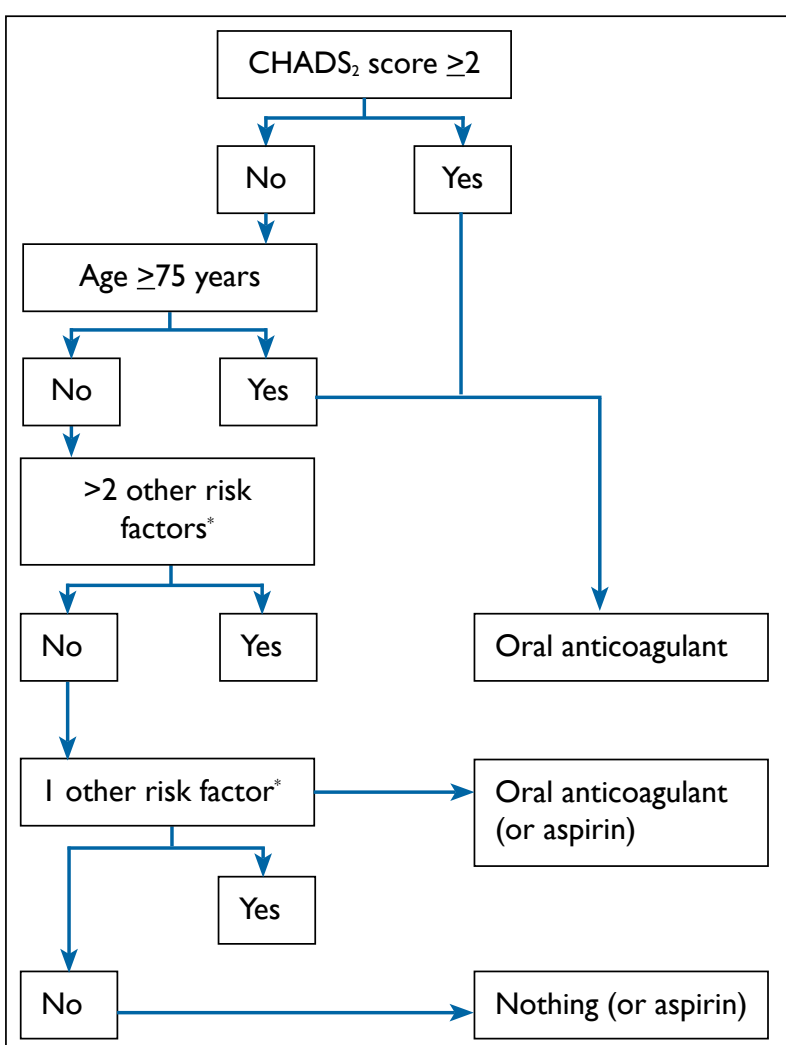

"Other clinically relevant non-major risk factors:Age 6574, female sex, vascular disease (as $\mathrm{CHA}_{2} \mathrm{DS}_{2}-\mathrm{VASc}$ ).

FIGURE I Clinical flowchart for the use of oral anticoagulant for stroke prevention in atrial fibrillation. From the European Society of Cardiology guidelines for the management of atrial fibrillation (2010)..$^{10}$

The HAS-BLED scoring tool for bleeding risk (Table 3) has also been incorporated into clinical guidelines to assist in anticoagulation decisions but it should be recognised that many of the risk factors for bleeding (including advancing age and previous stroke) are also strongly associated with thromboembolic stroke.

\section{Maintaining therapeutic anticoagulation with warfarin is challenging}

To achieve maximal therapeutic benefit for the prevention of ischaemic stroke it is important to achieve an INR of greater than two. However, exceeding an INR of 3.0 does not provide additional protection from ischaemic events but does result in a progressive increase in the likelihood of intra-cerebral haemorrhage. ${ }^{15}$ Achieving a stable, therapeutic INR may be easier in some patients than others but warfarin dosing can be a challenge and is influenced by genetic and dietary factors as well as concomitant medication. Gladstone et al. illustrated both the under-use of anticoagulants in patients with AF and the concerning proportion of patients receiving anticoagulation but with sub-therapeutic INR. In patients known to have AF presenting with a stroke, $39 \%$ of patients were receiving anticoagulant treatment (all warfarin) but only a quarter of the anticoagulated patients had an INR within the therapeutic range. Although the group with $A F$ who presented with a subsequent stroke or TIA were more likely to be receiving an anticoagulant (57\%), less than a third of these patients had an INR within the therapeutic range at presentation. ${ }^{16}$

Morgan and colleagues followed a group of over 6,000 Welsh patients with non-valvular AF.They demonstrated that in patients with AF at moderate or high risk for stroke, warfarin therapy is only effective at reducing the incidence of stroke if the target INR is achieved over $70 \%$ of the time. This is not often achieved in clinical practice. Furthermore, treatment with warfarin but with poor control (target INR achieved $<30 \%$ of the time) appeared to be harmful. ${ }^{17}$

\section{Therapeutic anticoagulation with warfarin is not immediate}

There is frequently a delay in achieving a therapeutic INR after recognition of the need for anticoagulation in patients with AF. This stems from the pharmacokinetics of warfarin and the requirement for loading doses before a stable therapeutic INR is achieved. In some instances, local requirements for warfarin therapy to be initiated via a dedicated anticoagulation clinic contribute to further delay. These factors may conspire to provide further time for left atrial thrombus to develop in the fibrillating heart. Irrespective of the ease and timing of achieving a stable INR and dosing regimen, warfarin therapy always requires monitoring. Regardless of age, this is inconvenient for the patient and is cumbersome and expensive for healthcare systems.

TABLE 4 Profiles of novel oral anticoagulants currently available. Adapted from Wisler and Becker (20I2). ${ }^{32}$

\begin{tabular}{|l|l|l|l|}
\hline & Dabigatran & Rivaroxaban & Apixaban \\
\hline Target & Factor Ila & Factor Xa & Factor Xa \\
\hline Dosing & Twice daily & Once daily & Twice daily \\
\hline Half-life (h) & $12-17$ & $5-13$ & $8-13$ \\
\hline Renal excretion (\%) & 80 & 33 & 25 \\
\hline Drug interactions & $\begin{array}{l}\text { Potent inhibitors of } \\
\text { P-glycoprotein (P-gP), reduce } \\
\text { dose with verapamil, avoid } \\
\text { dronedarone }\end{array}$ & $\begin{array}{l}\text { Potent inhibitors of cytochrome } \\
\text { P450 3A4 (CYP3A4) or } \\
\text { P-glycoprotein (P-gP) }\end{array}$ & $\begin{array}{l}\text { Potent inhibitors of P450 3A4 } \\
\text { (CYP3A4) or P-glycoprotein } \\
\text { (P-gP) }\end{array}$ \\
\hline
\end{tabular}




\section{NOVEL ORAL ANTICOAGULANTS}

The search for novel oral anticoagulants has been motivated by the drawbacks associated with warfarin. The pharmaceutical industry has been extremely competitive in the search for the ideal oral anticoagulant. Arguably, the perfect agent would have a rapid onset of action and predictable efficacy without the requirement for routine monitoring. It would protect from thromboembolism at least as well as warfarin and its haemorrhagic risk profile would be at least as safe, with the means to rapidly reverse its effect if required.

Ximelagatran was the first novel direct oral thrombin inhibitor to reach late phase trials and was granted approval for human use in several countries. It was hoped that this drug would replace warfarin but, after a considerable investment of time and finance, Ximelagatran was withdrawn in 2006 after significant hepatotoxic effects were observed.

Subsequent development proceeded and novel oral anticoagulants including dabigatran etexilate, rivaroxaban and apixaban are now available (Table 4). Furthermore, they are now supported by randomised controlled trial data to support their use in the prevention of thromboembolism in patients with $\mathrm{AF}^{18-20}$ Although developed with the same goal, the mechanisms of action, pharmacokinetic and pharmacodynamic profiles vary sufficiently that they may allow, or perhaps even require, tailoring of the choice of therapy depending on specific patient characteristics and requirements. Indeed, randomised controlled data reinforce this point although no direct comparison of these new agents has been performed, nor is this likely to occur. The three major novel oral anticoagulants currently available will be reviewed individually. It should be considered, however, that warfarin may remain the most appropriate treatment for a large number of patients with AF, particularly those already maintained with a stable regime and with an infrequent, convenient INR monitoring system in place. Other novel oral anticaogulants, including edoxaban, darexaban and betrixaban continue in development but detailed discussion of these agents is outside the scope of this review.

\section{Dabigatran etexilate}

Unlike rivaroxaban and apixaban, which both act to inhibit the coagulation cascade via antagonism of factor $X$, dabigatran is a direct thrombin (factor II) inhibitor. Administered as a prodrug, dabigatran etexilate is metabolised by plasma and liver esterases to the active moiety, dabigatran. This is a competitive, reversible antagonist of thrombin that reaches its peak plasma activity between 30 minutes and two hours after oral administration. It has a half-life of between 12 and 17 hours with approximately $80 \%$ of the dabigatran excreted unaltered by the kidneys. Based upon this and other pharmacokinetic data, its effects have been examined using twice daily dosing regimens without coagulation monitoring. ${ }^{21}$ It should be used with caution in patients receiving inhibitors of $\mathrm{P}$-glycoprotein (quinidine, verapamil, amiodarone, clarithromycin). Although the combination of dronedarone and dabigtran should be avoided, the combination of amiodarone and dabigatran does not require dosage alteration. The co-administration of potent inducers of P-glycoprotein such as phenytoin, carbamazepine, St John's wort and rifampicin should be avoided (Table 3). The use of dabigatran etexilate should be avoided in patients with an estimated glomerular filtration rate (eGFR) of less than $30 \mathrm{~mL} / \mathrm{min} / 1.73 \mathrm{~m}^{2}$ and in patients with severe liver disease.

The effect of dabigatran on thromboembolic complications in patients with AF was examined in the Randomised Evaluation of Long-term anticoagulant therapY (RE-LY) study. ${ }^{18}$ This trial recruited 18,II3 patients with $A F$ and at least one other risk factor for stroke and randomly assigned patients to either dabigatran $110 \mathrm{mg}$ twice daily (BD), dabigatran $150 \mathrm{mg}$ BD or warfarin with a target INR of 2-3.Those patients receiving dabigatran were blinded to the treatment dose received but warfarin administration was open-labelled. The mean $\mathrm{CHADS}_{2}$ score for those recruited was 2.1 and the mean age of patients was 71.5 years. Those receiving warfarin had an INR within target range for $64 \%$ of the time. This result is similar to other major trials to include patients receiving warfarin but may be greater than achieved outside the clinical trial environment.

At a dose of $150 \mathrm{mg} \mathrm{BD}$, dabigatran was associated with a significant reduction in ischaemic stroke or systemic embolism when compared with warfarin (I.I I\% per year vs $1.69 \%$ per year; hazard ratio [HR] 0.66 [confidence interval $(\mathrm{Cl}) 0.53-0.82] ; \mathrm{p}<0.00 \mathrm{I}$ ), while the result at the $110 \mathrm{mg}$ BD dose was not significantly different to warfarin. Of note, the converse dose-effect was noted when bleeding complications were assessed. Compared with those receiving warfarin, there was a trend toward fewer major haemorrhages in patients receiving dabigatran 150 $\mathrm{mg} \mathrm{BD}$ and this effect was statistically significant in those administered $110 \mathrm{mg}$ BD. There were 2.87 major bleeding episodes per year in those receiving dabigatran $110 \mathrm{mg}$ $\mathrm{BD}$ and 3.57 episodes per year in those receiving warfarin (HR 0.80 [ $\mathrm{Cl} 0.70-0.93] ; p=0.003$ ). Patients receiving dabigatran (both doses) reported a significantly greater incidence of dyspeptic symptoms than those taking warfarin. Intracranial bleeding is the most devastating complication of anticoagulant therapy. Both doses of dabigatran were associated with impressive reductions in intracranial haemorrhage when compared with warfarin (dabigatran etexilate $110 \mathrm{mg} \mathrm{BD:} \mathrm{HR} 0.30$ [Cl 0.19-0.45], $\mathrm{p}<0.00 \mathrm{I}$; dabigatran etexilate $150 \mathrm{mg}$ BD HR 0.40 [Cl $0.27-0.59$ ], $p<0.001$ ). ${ }^{22}$ 
Primarily based upon this trial data, the Scottish Medicines Consortium (SMC) has accepted dabigatran etexilate for use within National Health Service (NHS) Scotland for the prevention of stroke and systemic AF in patients with non-valvular AF. They specify that patients must also have one or more of the following risk factors to qualify: previous stroke, TIA or systemic embolism, left ventricular ejection fraction $<40 \%$, symptomatic heart failure, or age greater than 75 years. Patients aged 65 years or more qualify if they have diabetes mellitus, coronary artery disease or hypertension. They propose that the standard dose should be $150 \mathrm{mg}$ BD except for patients over the age of 80 who should receive the lower dose of $110 \mathrm{mg} \mathrm{BD}$. Based on the evidence from RE-LY they also suggest that in those patients younger than 80 years, a $110 \mathrm{mg}$ twice daily dose may be considered when the thromboembolic risk is low and the bleeding risk is high. ${ }^{23}$

Guidance from the National Institute for Health and Clinical Excellence (NICE) is similar and highlights the importance of discussion between patient and healthcare provider regarding the differences between warfarin and dabigatran. Furthermore, they highlight that any decision to change from warfarin therapy to dabigatran should be made in the context of current INR stability. ${ }^{24}$

\section{Rivaroxaban}

Rivaroxaban is an oral factor $\mathrm{Xa}$ inhibitor. Factor $\mathrm{Xa}$ is pivotal in the coagulation cascade as it is responsible for the conversion of prothrombin to biologically potent thrombin. Rivaroxaban has an onset of action approximately three to four hours after administration with predictable pharmacokinetics. Furthermore, there is little variation in pharmacodynamics in relation to age, sex or body weight. It has a half-life of between five and nine hours in healthy individuals and between nine and 13 hours in the elderly. ${ }^{25}$ It is administered as a once daily preparation. Around one-third of the drug is excreted via the kidneys while the remainder is metabolised by the liver. There are no reported food interactions with rivaroxaban and the propensity for drug interactions is said to be low. ${ }^{26}$ It is, however, recommended that the administration of potent inhibitors of cytochrome P450 3A4 (such as antifungal agents, chloramphenicol, clarithromycin, protease inhibitors) and inhibitors of P-glycoprotein (listed above) should be avoided. Rivaroxaban may be cautiously co-administered with potent inducers of cytochrome P450 3A4 (such as phenytoin, carbamazepine, phenobarbital and St John's wort) as well as inducers of P-glycoprotein (also listed above). It should be avoided in severe liver disease with coagulopathy, given at a reduced dose when the eGFR lies between $15-49 \mathrm{~mL} /$ $\min / 1.73 \mathrm{~m}^{2}$, and avoided completely when renal function is worse than this.
Randomised controlled trial data to support the use of rivaroxaban in patients with AF comes from the Rivaroxaban once daily, Oral, direct factor $\mathrm{Xa}$ inhibition Compared with vitamin $\mathrm{K}$ antagonism for prevention of stroke and Embolism Trial in Atrial Fibrillation (ROCKETAF). This study compared rivaroxaban $20 \mathrm{mg}$ OD (15 mg OD in patients with eGFR $15-49 \mathrm{~mL} / \mathrm{min} / 1.73 \mathrm{~m}^{2}$ ) with warfarin (target INR 2-3) in 14,264 patients with nonvalvular $\mathrm{AF}$ and a $\mathrm{CHADS}_{2}$ score of at least two. This comprised a higher risk group than those studied in RE-LY, with a mean CHADS 2 score of 3.47 and $55 \%$ of recruits having suffered a previous stroke, TIA or systemic embolism. Mean participant age was 73 years in both groups. Overall, warfarin therapy was less well controlled than in RE-LY with patients falling within target INR range for $58 \%$ of the time. ${ }^{19}$

After a mean follow-up of I.9 years, per-protocol analysis revealed an event rate for stroke, TIA or systemic embolism of $1.7 \%$ per year in the rivaroxaban group and $2.2 \%$ in the group treated with warfarin. Statistical analysis confirmed non-inferiority of rivaroxaban versus warfarin ( $\mathrm{HR} 0.79$ [Cl 0.66-0.96]; $\mathrm{p}<0.00 \mathrm{I})$. However, superiority of rivaroxaban was harder to demonstrate and only became statistically significant when investigators analysed the risk of stroke and systemic embolism in patients who remained on treatment over the course of 40 months ( $\mathrm{HR} 0.79$ [Cl 0.65-0.95]; $\mathrm{p}<0.0 \mathrm{I} 5)$. It was not found to be superior to warfarin in the stricter intentionto-treat analysis (HR 0.88 [Cl 0.74-I.03]; $\mathrm{p}=0.1 \mathrm{I}$ ).

Major bleeding and clinically relevant non-major bleeding rates were similar in both groups but, importantly, intracranial haemorrhage was less frequent in those receiving rivaroxaban $(0.49 \%$ per year vs. $0.74 \%$ per year; HR 0.67 [Cl 0.47-0.94]; $p=0.019) .{ }^{19}$

The SMC has considered the use of rivaroxaban in patients with non-valvular AF and one or more other risk factors for stroke. They approve the restricted use of rivaroxaban for patients who have poor INR control despite evidence that they are complying with a coumarin anticoagulant regimen. They also accept its use in patients who are allergic to or unable to tolerate coumarin anticoagulants. The SMC states that the once daily dosing schedule for rivaroxaban may confer some benefits to patients. Furthermore, its greater hepatic component to elimination may make it more suitable for patients with renal dysfunction. They recommend that patients with moderate to severe renal dysfunction receive a reduced dose of $15 \mathrm{mg}$ once daily. ${ }^{27}$ The National Institute for Health and Clinical Excellence has approved its use for the same patients either as a first choice anticoagulant or for those previously receiving warfarin. Again, they re-iterate the importance of an informed decision, particularly in the context of INR stability if a switch from warfarin is considered. ${ }^{28}$ 


\section{Apixaban}

Like rivaroxaban, apixaban is a direct factor $\mathrm{Xa}$ inhibitor. Its onset of maximal action is between one and three hours after dosing and it has a half-life of around 12 hours in healthy volunteers. Therefore twice daily dosing is recommended. Approximately $25 \%$ of its excretion is via the kidneys and other than interaction with potent inhibitors of the cytochrome P450 3A4, there is minimal reported drug interaction and advice on co-prescription is similar to that for rivaroxaban. It is suggested that it can be used with caution in patients with eGFR $15-29 \mathrm{~mL} / \mathrm{min} / 1.73 \mathrm{~m}^{2}$ and should be avoided if eGFR is less than $15 \mathrm{~mL} / \mathrm{min} / 1.73 \mathrm{~m}^{2}$. It should be noted, however that patients with eGFR $<25 \mathrm{~mL} / \mathrm{min} / 1.73 \mathrm{~m}^{2}$ were not included in the phase III clinical trial of patients with $\mathrm{AF}^{29}$ Its use should be avoided in patients with severe liver disease or liver disease associated with coagulopathy. The standard recommended dose is $5 \mathrm{mg} \mathrm{BD}$ but this should be reduced to $2.5 \mathrm{mg} \mathrm{BD}$ in patients over the age of 80 years, those with a body weight of $60 \mathrm{~kg}$ and below, or serum creatinine $\geq 132 \mu \mathrm{mol} / \mathrm{L}$.

The Apixaban for Reduction In Stroke and Other ThromboemboLic Events in atrial fibrillation (ARISTOTLE) trial provides the randomised controlled trial data to inform its use. ${ }^{20}$ Published in 20II, after RE-LY and ROCKET-AF, this trial recruited 18,201 patients with AF and at least one risk factor for stroke. Subjects were randomised to receive either warfarin (target INR 2-3)

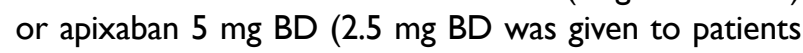
recommended for dose reduction based upon the factors noted above). The patients recruited were marginally younger than those recruited to RE-LY and ROCKET-AF (mean age of patients was 70 years) and their stroke risk was lower than those in ROCKET-AF, but similar to RE-LY (mean CHADS 2 score was 2.I); INR control was also similar to RE-LY, with patients spending an average of $62 \%$ of time within the target INR range.

After a median follow-up of 1.8 years, apixaban was shown to be superior to warfarin for the primary composite end-point of stroke or systemic embolism (apixaban: 1.27\% per year; warfarin: $1.60 \%$ per year; hazard ratio $(\mathrm{HR}) 0.79[\mathrm{Cl} 0.66-0.95] ; \mathrm{p}=0.01$ for superiority). In addition to this encouraging end-point, apixaban treatment was associated with fewer major bleeding events (HR $0.69[\mathrm{Cl} 0.60-0.80] ; p<0.00 \mathrm{I})$ and fewer haemorrhagic strokes ( $\mathrm{HR} 0.5 \mathrm{I}$ [Cl 0.35-0.75]; $\mathrm{p}<0.00 \mathrm{I})$. Furthermore, all-cause mortality was lower in the apixaban group (apixaban: $3.52 \%$ per year; warfarin: 3.94\%; HR 0.89 [Cl 0.80-0.99]; $p=0.047) .{ }^{20}$ There were no unexpected side-effects reported in patients taking apixaban and fewer patients stopped taking it than warfarin during the trial period. ${ }^{20}$

Apixaban has a variety of attractive properties, including less reliance upon renal excretion compared particularly with dabigatran, a good profile for tolerability as well as extremely encouraging clinical outcome data. Apixaban has had Food and Drug Administration (FDA) approval in the United States for the prevention of athromboembolic complications in patients with AF and has recently gained approval from both NICE and SMC for this indication.

\section{CAUTIOUS OPTIMISM FOR THE NOVEL ORAL ANTICOAGULANTS}

\section{Costs}

It is unclear whether the novel oral anticoagulants will eventually replace warfarin for thromboembolic stroke prevention in AF entirely. As with any new drug, particularly those for which there is a large eligible population, the financial cost of these agents has been a major concern for policy makers. While SMC and NICE have approved these three novel anticoagulants as outlined above and based upon a series of quality adjusted life year assessments, the true costs of these drugs remain to be seen. Unsurprisingly, the novel anticoagulants are more expensive than warfarin per se but there are also substantial costs inherent to current INR monitoring infrastructures. The potential for clinical benefit holds much greater emphasis for persuading policy changes rather than basing arguments simply on improved convenience for patients. As well as the obvious ethical element to this part of the argument, the large costs associated with caring for patients with either thromboembolic stroke or a haemorrhagic complication of anticoagulation need to be taken into account when making public health decisions.

\section{Monitoring}

Although some assays provide information, there is no standardised and routinely available method to give a quantification of the anticoagulant effect of the novel agents. ${ }^{25}$ It can be crucial or, at the very least, useful to understand the degree of anticoagulation at times of emergency treatment for haemorrhage, for surgical procedures or for the assessment of potential anticoagulant overdose. Although the lack of requirement for regular routine anticoagulation monitoring can be seen as one of the major advantages of the novel oral anticoagulants over warfarin this may also prove to be a drawback for a subset of patients for whom achieving a stable INR while taking warfarin may, in fact, be noncompliant with medication. By switching these patients to a novel agent without the means to easily assess compliance we may, inadvertently, select a non-compliant population for (under-) treatment with novel agents.

\section{Reversibility}

Unlike the effects of warfarin that may be reversed by vitamin $\mathrm{K}$, there is currently no simple antagonist to oppose the effects of the novel oral anticoagulants. This 
remains a concern although the anticoagulant effect of the novel agents is shorter acting than that of warfarin. Haemodialysis may be used in case of dabigatran overdose $^{30}$ in view of its predominantly renal excretion but other measures are non-specific and include the administration of exogenous factor VII or fresh frozen plasma. The pharmaceutical industry understands that this deficiency is one of the major barriers to more widespread uptake of the novel agents. Clinical development of antagonists continues at pace. ${ }^{31}$

\section{CONCLUSIONS}

The risk of thromboembolism as a consequence of AF is well documented and the need for safe, effective and convenient anticoagulation is clear. Clinical risk prediction tools and their incorporation into major guidelines have clarified those who stand to gain the most from anticoagulation. However, warfarin prescription remains sub-optimal and, even when it is prescribed, many patients spend a significant amount of time with a subtherapeutic INR. The requirement for regular INR monitoring is both inconvenient and costly.

\section{REFERENCES}

I Lloyd-Jones DM, Wang JJ, Leip EP et al. Lifetime risk for development of atrial fibrillation: the Framingham Heart Study Circulation 2004; I 10:1042-6. http://dx.doi.org/I0.II6I/0I. CIR.0000I40263.20897.42

2 Feinberg WM, Blackshear JL, Laupacis A et al. Prevalence, age distribution, and gender of patients with atrial fibrillation. Analysis and implications. Arch Intern Med 1995; 155:469-73. http://dx.doi. org/I0.100 I/archinte. I995.00430050045005

3 Stewart S, Hart CL, Hole DJ et al. Population prevalence, incidence, and predictors of atrial fibrillation in the Renfrew/Paisley study. Heart 200I; 86:5I6-2I. http://dx.doi.org/I0.1 I36/heart.86.5.5I6

4 Kannel WB, Wolf PA, Benjamin EJ et al. Prevalence, incidence, prognosis, and predisposing conditions for atrial fibrillation: population-based estimates. Am J Cardiol 1998; 82:2N-9N. http:// dx.doi.org/I0.1016/S0002-9149(98)00583-9

5 Lin HJ, Wolf PA, Kelly-Hayes $M$ et al. Stroke severity in atrial fibrillation. The Framingham Study. Stroke 1996; 27:1760-4. http:// dx.doi.org/I0.1 I6I/0I.STR.27.10.1760

6 Hart RG, Pearce LA, Aguilar MI. Meta-analysis: antithrombotic therapy to prevent stroke in patients who have nonvalvular atrial fibrillation. Ann Intern Med 2007; 146:857-67.

7 Olesen JB, Lip GY, Hansen ML et al.Validation of risk stratification schemes for predicting stroke and thromboembolism in patients with atrial fibrillation: nationwide cohort study. BMJ 20II; 342:dI24. http://dx.doi.org//0.1/36/bmj.dI 24

8 Scottish Intercollegiate Guidelines Network. Antithrombotics: indications and management (SIGN 129) [Internet]. Edinburgh: SIGN; 2012 [cited 2013 Feb 5]. Available from: http://www.sign. ac.uk/pdf/SIGNI29.pdf

9 National Institute for Health and Clinical Excellence. Atrial fibrillation (CG36) [Internet]. London: NICE; 2006 [cited 2013 Feb 5]. Available from: http://www.nice.org.uk/nicemedia/pdf/ CG036niceguideline.pdt

10 European Heart Rhythm Association, European Association for Cardio-Thoracic Surgery, Camm AJ et al. Guidelines for the management of atrial fibrillation: the Task Force for the Management of Atrial Fibrillation of the European Society of Cardiology (ESC). Eur Heart J 2010; 31:2369-429. http://dx.doi. org//0.1093/eurheartj/ehq278
The advent of novel oral anticoagulants promises a more predictable and convenient means to achieve anticoagulation. In addition to potential superiority over warfarin for the prevention of stroke, they also appear to be associated with fewer haemorrhagic effects including intracranial bleeding. Warfarin remains tried and tested with a wealth of clinical experience behind its use. However, understanding the important background to the novel agents presents an opportunity to tailor anticoagulant treatment, for example in the context of renal dysfunction, bleeding risk and concomitant medication. The most satisfactory prescribing policy for these agents will depend on both financial considerations and an appreciation of the positive and negative aspects of the novel agents. However, the development of yet more preparations, and eventually antidotes, will allow treatment of a greater proportion of the large population with AF who are currently left overexposed to the devastating consequences of thromboembolic stroke.

I I Camm AJ, Lip GY, De Caterina R et al. 2012 focused update of the ESC Guidelines for the management of atrial fibrillation: an update of the 2010 ESC Guidelines for the management of atrial fibrillation. Developed with the special contribution of the European Heart Rhythm Association. Eur Heart J 2012; 33:27I9_ 47. http://dx.doi.org/10.1093/eurheartj/ehs253

I2 Lane DA, Lip GY. Barriers to anticoagulation in patients with atrial fibrillation: changing physician-related factors. Stroke 2008; 39:7-9. http://dx.doi.org/I0.I I6I/STROKEAHA.I07.496554

I 3 Nieuwlaat R, Capucci A, Lip GY et al.Antithrombotic treatment in real-life atrial fibrillation patients: a report from the Euro Heart Survey on Atrial Fibrillation. Eur Heart J 2006; 27:30 I8-26. http:// dx.doi.org/I0.1093/eurheartj/ehl0I5

I4 Mant J, Hobbs FD, Fletcher $\mathrm{K}$ et al. Warfarin versus aspirin for stroke prevention in an elderly community population with atrial fibrillation (the Birmingham Atrial Fibrillation Treatment of the Aged Study, BAFTA): a randomised controlled trial. Lancet 2007; 370:493-503. http://dx.doi.org/I0.10 I6/S0 I40-6736(07)6 I233-I

15 Odén A, Fahlén M, Hart RG. Optimal INR for prevention of stroke and death in atrial fibrillation: a critical appraisal. Thromb Res 2006; I 17:493-9. http://dx.doi.org/10.10 I6/j.thromres.2004.II.025

16 Gladstone DJ, Buie E, Fang J et al. Potentially preventable strokes in high-risk patients with atrial fibrillation who are not adequately anticoagulated. Stroke 2009; 40:235-40. http://dx.doi.org/I0.I I6I// STROKEAHA. 108.516344

17 Morgan CL, McEwan P, Tukiendorf A et al. Warfarin treatment in patients with atrial fibrillation: observing outcomes associated with varying levels of INR control. Thromb Res 2009; I24:37-4I. http://dx.doi.org/10.1016/j.thromres.2008.09.016

I8 Connolly SJ, Ezekowitz MD, Yusuf S et al. Dabigatran versus warfarin in patients with atrial fibrillation. $N$ Engl J Med 2009; 36I:I I39-5I. http://dx.doi.org/I0.1056/NEJMoa090556 I

19 Patel MR, Mahaffey KW, Garg J et al. Rivaroxaban versus warfarin in nonvalvular atrial fibrillation. $N$ Engl J Med 20II; 365:883-9l. http://dx.doi.org/I0.1056/NEJMoa I009638

20 Granger CB, Alexander JH, McMurray JJ et al. Apixaban versus warfarin in patients with atrial fibrillation. $N$ Engl J Med 20II; 365:98I-92. http://dx.doi.org/I0.I056/NEJMoal I07039 
2I Ezekowitz MD, Connolly S, Parekh A et al. Rationale and design of RE-LY: randomized evaluation of long-term anticoagulant therapy, warfarin, compared with dabigatran. Am Heart J 2009; I 57:805-I0. 8I0.el-2.

22 Hart RG, Diener HC, Yang S et al. Intracranial hemorrhage in atrial fibrillation patients during anticoagulation with warfarin or dabigatran: the RE-LY trial. Stroke 2012; 43:15II-7. http://dx.doi. org/I0. I I6I/STROKEAHA. I I2.6506/4

23 Scottish Medicines Consortium. Dabigatran etexilate $110 \mathrm{mg}$ and 150mg hard capsules (Pradaxaß) (SMC No. 672/II) [Internet]. Glasgow: SMC; 2011 [cited 2013 Feb 5]. Available from: http:// www.scottishmedicines.org.uk/files/advice/dabigatran_Pradaxa_ FINAL_August_20I I_Amended_05.09.II_for_website.pdf

24 National Institute for Health and Clinical Excellence. Dabigatran etexilate for the prevention of stroke and systemic embolism in atrial fibrillation (TA249) [Internet]. London: NICE; 2012 [cited 2013 Feb 5]. Available from: http://publications.nice.org.uk/dabigatranetexilate-for-the-prevention-of-stroke-and-systemic-embolism-inatrial-fibrillation-ta249

25 Potpara TS, Lip GY, Apostolakis S. New anticoagulant treatments to protect against stroke in atrial fibrillation. Heart 20I 2; 98: I34I7. http://dx.doi.org/I0.II36/heartjnl-2012-30184 I

26 ROCKET AF Study Investigators. Rivaroxaban-once daily, oral, direct factor $\mathrm{Xa}$ inhibition compared with vitamin $\mathrm{K}$ antagonism for prevention of stroke and Embolism Trial in Atrial Fibrillation: rationale and design of the ROCKET AF study. Am Heart J 2010 I59:340-7.el.
27 Scottish Medicines Consortium. Rivaroxaban 15 and 20mg filmcoated tablets (Xarelto®) (SMC No. 756//2) [Internet]. Glasgow: SMC; 2012 [cited 2013 Feb 5]. Available from: http://www. scottishmedicines.org.uk/files/advice/rivaroxaban_Xarelto_for_ AF_FINAL_Jan_20I2_for_website.pd

28 National Institute for Health and Clinical Excellence. Rivaroxaban for the prevention of stroke and systemic embolism in people with atrial fibrillation (TA256) [Internet]. London: NICE; 2012 [cited 2013 Feb 5]. Available from: http://www.nice.org.uk/nicemedia/ live// 3746/59295/59295.pdf

29 Lopes RD, Alexander JH, Al-Khatib SM et al. Apixaban for reduction in stroke and other ThromboemboLic events in atrial fibrillation (ARISTOTLE) trial: design and rationale. Am Heart J 2010; I59:33 I-9. http://dx.doi.org/I0.10 I6/j.ahj.2009.07.035

30 Woo JS, Kapadia N, Phanco SE et al. Positive outcome after intentional overdose of dabigatran.J MedToxicol 20I2. Forthcoming. http://dx.doi.org//0.1007/s I 3 I8I-0I2-0276-5

31 Ahrens I, Peter K, Lip GY et al. Development and clinical applications of novel oral anticoagulants. Part II. Drugs under clinical investigation. Discov Med 2012; 13:445-50.

32 Wisler JW, Becker RC.A guidance pathway for the selection of novel anticoagulants in the treatment of atrial fibrillation. Crit Pathw Cardiol 20I2; I :55-6I. http://dx.doi.org/I0.1097/HPC.0b0I3e31825298ef

\section{INVITATION TO SUBMIT PAPERS}

We would like to extend an invitation to all readers of The Journal of the Royal College of Physicians of Edinburgh to contribute original material, especially to the clinical section. The JRCPE is a peer-reviewed journal with a circulation of 8,000 . It is also available open access online. Its aim is to publish a range of clinical, educational and historical material of cross-specialty interest to the College's international membership.

The JRCPE is currently indexed in Medline, Embase, Google Scholar and the Directory of Open Access Journals. The editorial team is keen to continue to improve both the quality of content and its relevance to clinical practice for Fellows and Members. All papers are subject to peer review and our turnaround time for a decision averages only eight weeks.

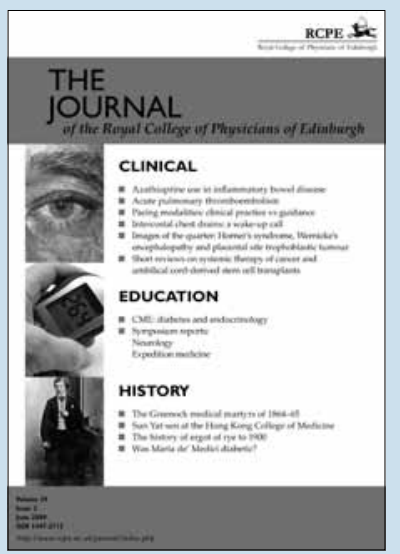

We would be pleased to consider submissions based on original clinical research, including pilot studies. The JRCPE is a particularly good forum for research performed by junior doctors under consultant supervision. We would also consider clinical audits where the 'loop has been closed' and a demonstrable clinical benefit has resulted.

For further information about submissions, please visit: http://www.rcpe.ac.uk/journal/contributers.php or e-mail editorial@rcpe.ac.uk.Thank you for your interest in the College's journal.

The editorial team,

The Journal of the Royal College of Physicians of Edinburgh 